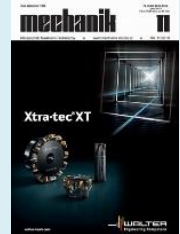

Author: Jerzy Madej

Title of article: „Analiza nośności połączenia wciskowego” („A strength analysis of the interference-fit joints”)

Mechanik, Vol. 91, No. 11 (2018): pages 1032-1034

DOI: https://doi.org/10.17814/mechanik.2018.11.185

\title{
A strength analysis of the interference-fit joints
}

\section{Analiza nośności połączenia wciskowego}

\section{JERZY MADEJ *}

The analysis of interference-fit joints process and theirs strength, by finite element method (FEM) in FEMAP v. 11.2 numerical system is presented. The results of the analysis are compared with the numerical results obtained with the Lame calculations. All results were also verified experimentally with the MTS measurement system.

KEYWORDS: interference-fit joints, numerical methods, strength test

Interference-fit connections are widely used in engineering constructions, especially when connecting the shaft with the rotor in the construction of electric motors. Combinations of this type were analyzed in various aspects in many works [1-5], but there are few experimental studies verifying the results of numerical calculations regarding the load-bearing capacity of these joints.

In the interference-fit connection, mutual fixing of the connected parts takes place due to the friction caused by the interference. The disconnection of the parts is counteracted by the contact forces caused by the deformation of the connected parts. The initial difference in the dimensions of the shaft and the bore hole as well as the mechanical properties of the materials to be joined affect the load capacity of the connection.

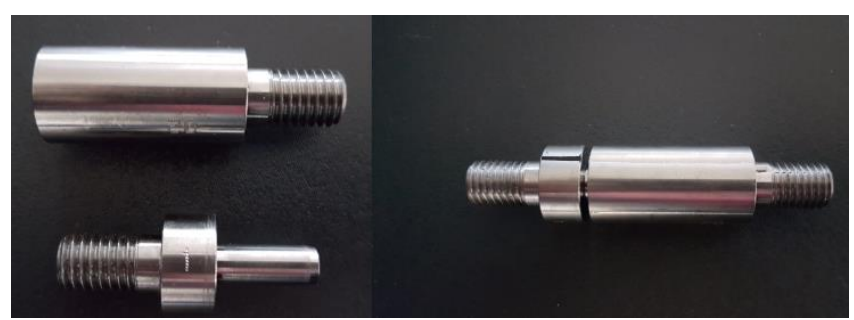

Fig. 1. Roller and binding before folding and after folding

In order to determine contact pressures and determine the load capacity of a press fit connection, most often the formulas resulting from the analogy to the circularsymmetric task of Lame, i.e. a flexible thick-walled shell (pipe) operating under pressure, are used.

\footnotetext{
* Dr hab. inż. Jerzy Madej (juma@ath.bielsko.pl) Akademia Techniczno-Humanistyczna w Bielsku-Białej
}

In this work, on the example of a selected shaft and hub assembly, the breaking strength value obtained from the Lame formula was compared with the result of numerical simulation and experimental verification of the results was made.

\section{Subject of the analysis}

The subject of the analysis was the press fit connection of the shaft and the hub (fig. 1). The shaft with a length of 20 $\mathrm{mm}$ and a diameter of $\varnothing 8 \mathrm{r} 6$ has a measuring diameter of $8.017 \mathrm{~mm}$. The total length of the hub is $40 \mathrm{~mm}$, the outer diameter is $20 \mathrm{~mm}$ and the internal diameter is $\varnothing 8 \mathrm{H} 7$. The measuring diameter is $8.005 \mathrm{~mm}$. The interference value $\Delta$ is equal to half the difference of deviations of the elements made and amounts to $0.006 \mathrm{~mm}$.

According to Lamé's analogy, the condition of cooperation of the interference-fit connection is the difference between the radius of the inner hub and the radius of the outer shaft. As a result of erasing the interference, the radii of the cooperating surfaces level out, and on these surfaces $p_{\mathrm{s}}$ pressure equal to the radial stress works (fig. 2).

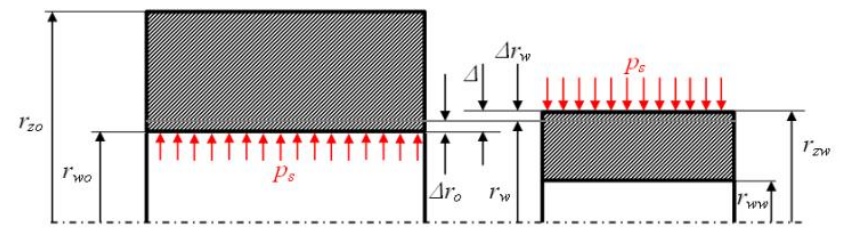

Fig. 2. Concept of Lame's analogy

This pressure can be calculated from the formula:

$$
p_{\mathrm{s}}=\sigma_{\mathrm{r}}=\frac{\mathrm{E} \Delta\left(r_{\mathrm{w}}^{2}-r_{\mathrm{ww}}^{2}\right)\left(r_{\mathrm{zo}}^{2}-r_{\mathrm{w}}^{2}\right)}{2\left(r_{\mathrm{zo}}^{2}-r_{\mathrm{ww}}^{2}\right) r_{\mathrm{w}}^{3}}
$$

where:

$E$ - Young's modulus,

$\Delta=\Delta r_{\mathrm{o}}-\Delta r_{\mathrm{w}}-$ push,

$r_{\mathrm{w}}$ - external radius of the shaft,

$r_{w w}$ - inner radius of the shaft,

$r_{\mathrm{zo}}$ - outer radius of the hub. 

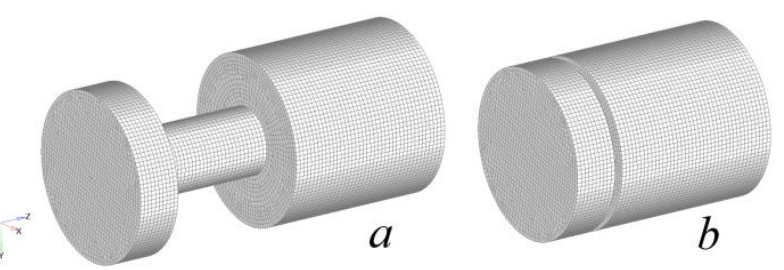

Fig. 3. Discrete model in the configuration: a) output and b) final, after pressing
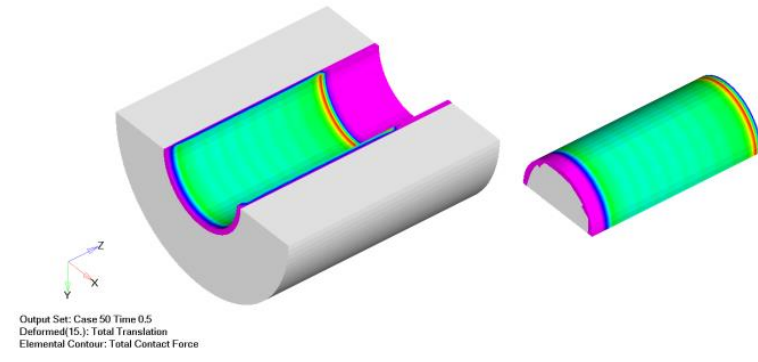

Fig. 4. Distribution of contact forces in the hole and shaft - section in the $x-z$ plane
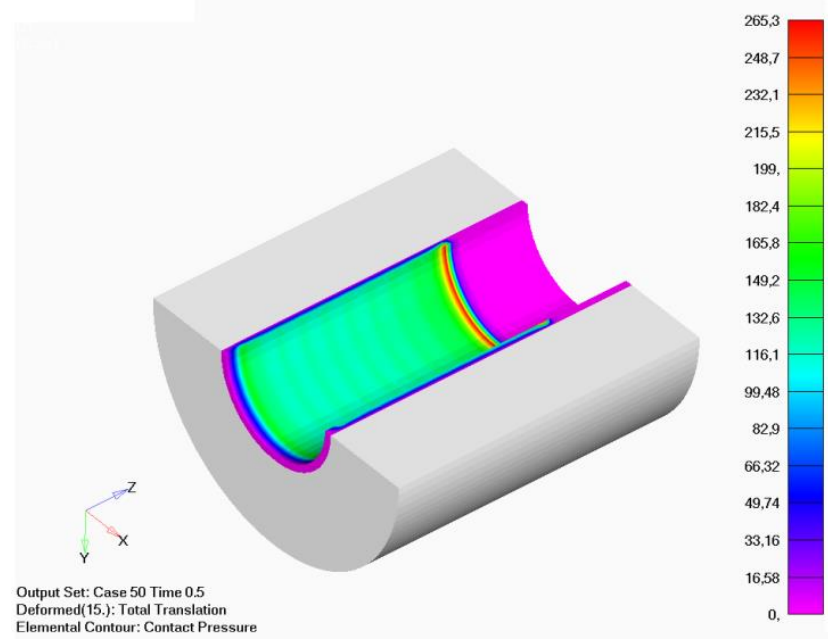

Fig. 5. Distribution of contact pressure on the contact surface

In the case under consideration, the shaft is not hollow, therefore $r_{\mathrm{ww}}=0, r_{\mathrm{w}}=4.006 \mathrm{~mm}, r_{\mathrm{zo}}=10 \mathrm{~mm}$, and the interference value is $0.006 \mathrm{~mm}$. The contact pressure value according to formula (1) is $132.3 \mathrm{MPa}$.

If it is assumed that the coefficient of friction for steel $\mu=$ 0.1 , the length of the interference-fit connection $I=15 \mathrm{~mm}$, and the shaft diameter $d=8 \mathrm{~mm}$, the load capacity of the joint when loaded with the longitudinal force $F$ is:

$$
F=\mu \cdot \sigma_{r} \cdot \pi \cdot d \cdot I=0,1 \cdot 132,3 \cdot \pi \cdot 8 \cdot 15=4987,6 \mathrm{~N}
$$

\section{Numeric simulation}

The process of making a press fit connection was modeled in the FEMAP v. 11.2 program. It was assumed that Young's modulus is $2.1 \cdot 10^{5}$ and Poisson's ratio is 0.3 . It was assumed that the external surface of the shaft and the inner surface of the hub are contact surfaces, and the entire dimensional deviation of $0.006 \mathrm{~mm}$ has been assigned to the shaft.

The discrete model of the shaft and sleeve in the initial configuration is presented in fig. 3 . It has been divided with a hexagonal mesh into three-dimensional elements with dimensions of $1 \mathrm{~mm}$.
The simulation was carried out using advanced, nonlinear static analysis. In this analysis, the load was implemented in two stages in 100 subsequent steps with a step value equal to 0.01 . The first load step, defined as the displacement of the shaft face, was carried out in 50 steps, which corresponds to a displacement of $0.3 \mathrm{~mm}$ in each step.

Fig. 4 shows the distribution of contact forces on the surface of the shaft and the housing bore after pressing 15 $\mathrm{mm}$. The maximum value of the contact force is $66.69 \mathrm{~N}$.

Fig. 5 presents the distribution of contact pressure at the contact surface in the hub. It is a maximum of $256 \mathrm{MPa}$ and it differs by $124 \mathrm{MPa}$ from the value of pressure obtained from Lame's designs.

In the second stage, a $100 \mathrm{~N} / \mathrm{mm}^{2}$ load was applied to the wider base of the shaft, carried out in the next 50 steps, which corresponds to a load of $2 \mathrm{~N} / \mathrm{mm}^{2}$ in each load step.

A noticeable decrease in contact stresses occurred in the eighth load step, which corresponds to a load of $16 \mathrm{~N} / \mathrm{mm}^{2}$ or a concentrated force of about $6000 \mathrm{~N}$ compared to 5000 $\mathrm{N}$ obtained from the Lame formula.

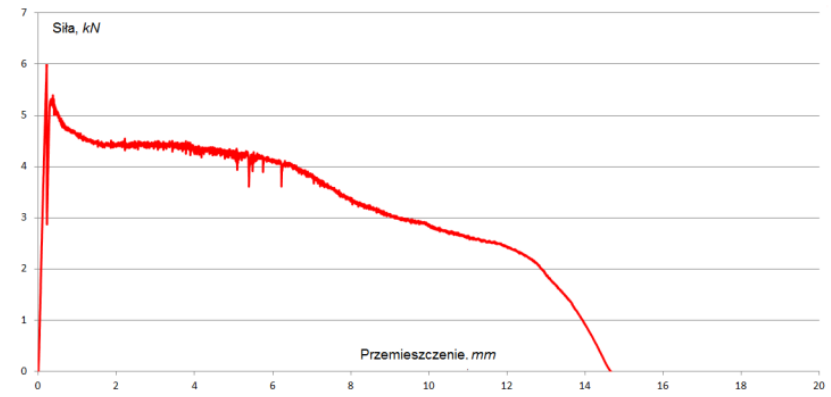

Fig. 6. Diagram of the dependence of force on displacement from the moment of initial breaking of the connection until the shaft comes out of the hub completely

\section{Experimental tests of the press fit connection}

In order to verify the numerical calculations, the damage tests of press fit connection were performed. They use a measuring device consisting of an MTS actuator equipped with a force sensor, a displacement sensor and a mounting adapter.

The force graph of disasembly the interference-fit connection led to the complete protrusion of the shaft from the hub is shown in fig. 6 .

As can be seen from the graph (fig. 6), the connection was broken after reaching a force equal to $6000 \mathrm{~N}$.

\section{Conclusions}

The numerical calculations carried out with the use of FEM, verified experimentally, showed that the use of Lamé's formulas to determine the load-bearing capacity of the interference-fit connections gives an estimation with a deficiency. This adversely affects the optimal use of the connection capability in the field of load transfer. The difference in the value of the maximum force causing the breaking of the contact stress in relation to the force obtained from the formula (2) is as much as $20 \%$. It should be assumed that this difference can be multiplied in the case of larger dimensions of the shaft-hub assembly or larger dimensional deviations, which will be subject to further analysis. 


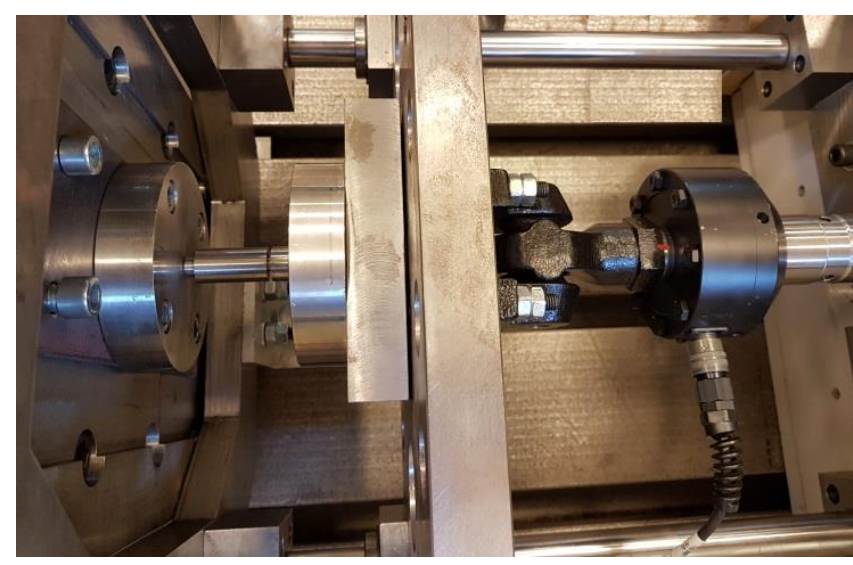

Fig. 7. MTS actuator with adapter fixing the connection

Lamé's problem as a circularly symmetric task assumes zero tangential stress values, which in the case of interference-fit connections is an erroneous assumption, so the contact pressure value determined from formula (1) can only be used as an approximate estimate of the contact pressure in the connection.

\section{REFERENCES}

1. Cajuhi A.J., Pepe I.M. "Using finite element analysis and strain gauge experimental data to evaluate stress concentration factor on press-fit assembly". 20 $0^{\text {th }}$ International Congress of Mechanical Engineering. Gramado, RS, Brazil (2009): pp. 15-20.

2. Gallio G. i in. "Study of the interference contribution on the performance of an adhesive bonded press-fitted cylindrical joint". Int. Journal of Adhesion \& Adhesives. 53 (2014): pp. 8996.

3. Hüyük H. i in. "Analysis of elastic-plastic interference-fit joints". Procedia Engineering. 81 (2014): pp. 2030-2035.

4. Croccolo D., Vincenzi N. "Stress concentration factors in compression-fit couplings". J. Mechanical Engineering Science. 224, C (2009): pp. 1143-1151.

5. Sinitsyna V., Sinitsyn A. "Finite-element analysis of parts stress state of tight joint assembled by press fitting". Modern Mechanical Engineering. 4 (2014): pp. 198-206.

Translation of scientific articles, their computer composition and publishing them on the website www.mechanik.media.pl by original articles in Polish is a task financed from the funds of the Ministry of Science and Higher Education designated for dissemination of science. 